\title{
ESTRATÉGIAS DE MARKETING DIGITAL UTILIZADAS PELA SÉRIE DE TELEVISÃO GREY'S ANATOMY NA MÍDIA SOCIAL INSTAGRAM ${ }^{1}$
}

\author{
DIGITAL MARKETING STRATEGIES USED BY \\ GREY'S ANATOMY ON INSTAGRAM SOCIAL MEDIA
}

\author{
Ricardo Acosta Biguelini² e Claudia Buzatti Souto ${ }^{3}$
}

\section{RESUMO}

O estudo da relação entre marketing digital, produção de conteúdo, mídia social, mais especificamente o Instagram e uma série de televisão como Grey’s Anatomy, tem se tornado interesse no âmbito acadêmico de diversas maneiras, considerando o número de usuários da plataforma e a popularização dos seriados. Para o presente estudo definiu-se previamente como objetivo geral analisar as estratégias de marketing digital utilizadas para divulgação do seriado, durante a exibição da $15^{\mathrm{a}}$ temporada, na rede social Instagram, mapeando-as, identificando os tipos de conteúdo disponibilizados pela $\mathrm{ABC}$ na plataforma e verificando como as postagens influenciam no engajamento dos seguidores. Para chegar aos resultados foi utilizada a metodologia quali-quantitativa e como método a análise de conteúdo. Os resultados da pesquisa mostraram que apesar da utilização de diferentes técnicas de marketing digital e de conteúdos os seguidores têm preferências por postagens que apresentam os atores e personagens que fazem parte do seriado.

Palavras-chave: Comunicação. Publicidade e Propaganda. Marketing Digital. Instagram. Engajamento.

\section{ABSTRACT}

Studying the relationship between digital marketing, content production, social media, more specifically Instagram, and a television series like Grey's Anatomy, has become interesting in academia in a number of ways, considering the number of users of the platform and the popularization of content. series. For the present study, it was previously defined as a general objective to analyze the digital marketing strategies used to publicize the show during the 15th season exhibition on the Instagram social network, mapping them, identifying the types of content provided by ABC on the platform and checking how posts influence the engagement of followers. To reach the results, the qualitative and quantitative methodology was used and the content analysis method. The survey results showed that despite the use of different digital marketing and content techniques, followers have preferences for posts featuring the actors and characters that are part of the show.

Keywords: Communication. Advertising and marketing. Digital marketing. Instagram. Engagement.

1 Artigo resultante da disciplina Trabalho Final de Graduação II do curso de Publicidade e Propaganda da UFN.

2 Bacharel em Publicidade e Propaganda - Universidade Franciscana. E-mail: ricardoacostabiguelini@gmail.com 3 Orientadora. Professora do Curso de Publicidade e Propaganda da Universidade Franciscana. E-mail: claudiabsouto@ hotmail.com 


\section{INTRODUÇÃO}

Com a popularização da tecnologia e das redes sociais a comunicação precisou adaptar-se, ficou mais rápida, incorporou novos formatos e outros veículos foram criados. $\mathrm{O}$ surgimento da internet facilitou o acesso à comunicação, pois em outros tempos necessitava-se de uma televisão ou de assinaturas de jornal, por exemplo, para estar conectado com os acontecimentos locais ou mundiais. Hoje é possível acessar informações na "palma da mão", pois com o desenvolvimento da internet essa disponibilidade se tornou alcançável através de dispositivos móveis como smartphones e tablets.

A partir da criação de redes sociais como Instagram e Facebook as pessoas passaram a ficar a um "aplicativo" de distância, por não estarem mais sujeitas a limitações geográficas ou de meios de comunicação como o telefone ou o correio, possibilitando assim, uma intercomunicação mais rápida e praticamente instantânea. As marcas não ficaram atrás e direcionaram seus investimentos para as redes sociais, já que essa ambiência possui versões para ser utilizada pelas empresas, possibilitando a inserção de anúncios pagos em diferentes formatos.

Tendo em vista a necessidade de estar presente em uma mídia diferenciada, as estratégias de comunicação, até então utilizadas, necessitam de atualização para se adaptar ao formato empregado na internet, favorecendo o surgimento de novas técnicas para comunicação, assim como de mensuração de resultados para redes sociais. De acordo com Lupetti (2007, p. 105) estratégias de comunicação "se referem às ações que deverão ser planejadas e executadas a partir do tipo de campanha escolhida e de determinadas informações". As definições da autora, embora façam referência a ambiência off-line, permitem contextualizar uma ação publicitária nos dias atuais, pois levam em consideração principalmente o tipo de material de divulgação e a necessidade de possuir um acervo de informações sobre o público para quem essa comunicação será direcionada.

Atualmente as marcas estão focadas em produção de conteúdo relevante para o público-alvo no intuito de angariar engajamento, pois assim é possível despertar a atenção do público pretendido nas redes sociais. Como afirma Kotler (2017, p. 36) "mídias sociais como Twitter e Instagram facultam aos seus usuários mostrar e compartilhar suas experiências como clientes, inspirando outros consumidores [...] a buscar uma experiência semelhante". Estar presente nas redes sociais dos consumidores da marca, com conteúdo interessante é tão importante quanto o ato de venda, pois como explica o autor, consumidores influenciam outros consumidores a partir de opiniões sobre a marca, instigam a curiosidade e a conhecer determinado produto.

O Instagram coloca-se em evidência para investimentos publicitários e disponibilizando espaço para influenciadores digitais, o termo faz referência às pessoas que se destacam nas redes e que possuem a capacidade de mobilizar um grande número de seguidores, pautando opiniões e comportamentos e até mesmo criando conteúdos que sejam exclusivos (SILVA; TESSAROLO, 2016). 
A plataforma se tornou um fenômeno entre pessoas de todas as idades, pois permite publicações de diversos formatos e dispõe de ferramentas para produzir conteúdo para o público-alvo de diferentes marcas.

A rede social também é utilizada em estudos relacionados à área da moda, como exemplo, na universidade de Lisboa em 2018 a pesquisa intitulada "A cultura e o branding de moda na comunicação digital: o Instagram e a geração de sentidos" (RIBEIRO, 2018), utilizando o perfil das marcas H\&M e Gucci. Foi possível encontrar também pesquisas relacionadas à temática na área da publicidade, um dos trabalhos que merece destaque, foi o estudo intitulado "A presença digital no Instagram da marca Adidas 2017” (TRINDADE, 2017) desenvolvido em 2017 na Universidade Franciscana. A autora realizou uma análise da presença digital da marca Adidas na plataforma digital, que destaca como a empresa desenvolve a comunicação na plataforma mapeando características e diferenças, nos perfis da empresa examinada. A rede social também foi tema de trabalhos na área da comunicação nos últimos cinco anos, a questão de como os fãs reagem a spoilers ${ }^{4}$ no Twitter, um estudo feito a partir de páginas de fãs, é um exemplo de como a plataforma foi analisada na perspectiva publicitária. Entretanto, durante a realização do estado da arte que balizou o presente artigo não foi identificado um estudo relacionado especificamente às estratégias de comunicação de séries no Instagram e como se caracterizam.

Tendo em vista os estudos empíricos realizados para a estruturação do presente artigo é possível depreender que a plataforma possui versatilidade em termos de disponibilidade de formatos para postagem e diferentes tipos de conteúdo. A variedade de possibilidades de publicações desperta o interesse em áreas distintas, incluindo, como no caso da proposta a ser estudada, a produção de conteúdo para uma série de televisão.

Seriados de televisão e serviços de streaming 5 , como a Netflix, vêm sendo estudados há alguns anos, inserindo as séries no cenário acadêmico como objetos de estudo por diferentes áreas. Utilizada como foco de pesquisa, a série Grey’s Anatomy já foi analisada pela área da medicina, para entender como a trama influência na relação paciente médico, a partir da perspectiva do discurso feminista e a relação pró direitos civis presente na série também foi referência.

O seriado Grey's Anatomy criado pela Shonda Rhimes, que está em exibição desde 2005 e em 2019 finalizou a 15ª temporada é um drama que acompanha a trajetória de Meredith Grey e seus colegas em um hospital na cidade de Seattle nos Estados Unidos. Também originou dois spinofss ${ }^{6}$,

4 O dicionário Oxford define spoilers como "uma descrição de um desenvolvimento importante da trama em um programa de televisão, filme ou livro que, se conhecido anteriormente, pode reduzir a surpresa ou suspense para um espectador ou leitor iniciante" (tradução livre do autor, Oxford, online).

5 Streaming (fluxo de mídia, software de transmissão online) é uma forma de distribuição de dados, geralmente de multimídia em uma rede através de pacotes. É frequentemente utilizada para distribuir conteúdo multimídia através da Internet (REVOREDO, 2017).

6 De acordo com Bellamy, etal (2009) "Um programa spin off é definido por um programa derivado de um outro já existente, comumente se apropriando dos personagens" (tradução livre do autor). 
Private Practice (2007 - 2013) e Station 19 (2018 - Atualidade) que conta com episódios crossovers $^{7}$ entre os dois seriados, dando margem para novas histórias com personagens que já haviam fechado seu ciclo relevante para trama principal do seriado.

A compreensão de como pode ser estabelecida a comunicação nesta ambiência digital é importante para que se possa encontrar as formas mais adequadas de estabelecer o contato com o público. Uma das técnicas utilizadas é a mensuração da taxa de engajamento, que permite identificar a recepção da postagem perante os seguidores da marca, levando em consideração o consumidor, o conteúdo postado e a reação dos seguidores. Esta técnica não leva em consideração se as reações são positivas ou negativas, mas sim o conjunto de comentários, reações e compartilhamentos, independentemente do seu conteúdo.

Desse modo, levando em consideração as informações apresentadas o problema de pesquisa foi definido da seguinte maneira: como se configuram as estratégias de marketing digital utilizadas para a série de televisão Grey’s Anatomy na mídia social Instagram durante o período de veiculação da $15^{\text {a }}$ temporada? E como objetivo geral estudar as estratégias de marketing digital da série de televisão Grey's Anatomy, durante a exibição da $15^{\mathrm{a}}$ temporada, na mídia social Instagram. A definição dos objetivos específicos, que indicam os caminhos desta pesquisa, foram: (i) mapear as estratégias de marketing digital utilizadas pela ABC no Instagram @abcgreys no período de exibição da $15^{\mathrm{a}}$ temporada; (ii) identificar os diferentes tipos de conteúdo postados; (iii) verificar como as postagens influenciam no engajamento dos seguidores.

O estudo da relação entre marketing digital, produção de conteúdo, mídia social, mais especificamente o Instagram e uma série de televisão com Grey’s Anatomy, tem se tornado interesse no âmbito acadêmico de diversas maneiras. É importante levar em consideração o número de usuários da plataforma e a popularização dos seriados, o que fez com que marcas e empresas tomassem iniciativas e se posicionassem sentido de utilizar técnicas de marketing digital e conteúdo para alcançar novos consumidores e consequentemente gerar lucro. O estudo destes mecanismos é importante para poder caracterizar como estabelecem o contato com os seguidores das marcas e ainda como funciona o processo de mensuração de resultados nesta circunstância específica.

\section{MARKETING E PRODUÇÃO DE CONTEÚDO DIGITAL}

As mudanças proporcionadas pelo avanço da tecnologia fomentaram a atualização nas técnicas de marketing até então utilizadas. A empresa Resultados Digitais (2018, p. 5) define marketing digital como "um conjunto de informações e ações que podem ser feitas em diversos meios digitais com objetivo de promover empresas e produtos". O surgimento das redes sociais favoreceu o ingresso

7 O dicionário Oxford define crossover como "um ponto ou lugar de cruzamento entre um lado e outro". 
de marcas no meio online criando uma economia digital focada em ações específicas, reformulando a maneira que costumavam se relacionar com os consumidores.

No modelo tradicional de marketing e publicidade as marcas se dirigem ao consumidor utilizando peças de comunicação em canais de mídia para impactá-lo e gerar o desejo de compra. Neste modelo o consumidor ficava totalmente passivo diante dos canais de mídia como TV, rádio, revistas e jornais. (STRUTZEL, 2015, p. 7).

O modelo clássico de propaganda ficou desatualizado devido a mudança no comportamento do consumidor que antes tinha uma postura passiva perante a comunicação a que era exposto. E atualmente é possível dizer que está mais ativo, pois de acordo com Strutzel (2015) o usuário tem iniciativa e dispõe de ferramentas antes não disponíveis, para buscar informações sobre produtos e serviços quando e onde quiser. "Em números significa dizer que $60 \%$ do processo de compra já foi realizado antes mesmo de o consumidor entrar em contato com o vendedor" (RESULTADOS DIGITAIS, 2018, p. 4), essa informação fez com que o processo de compra se expandisse, devido a mudança de como o cliente faz suas compras.

Conforme Strutzel (2015, p. 7), “o poder conquistado pelo usuário e a exigência de uma boa experiência de consumo obrigaram as marcas a abandonar a comunicação em massa para adotar o relacionamento segmentado". E para isso é necessário conhecer os usuários do produto ou serviço e tornar a informação mais próxima dos seguidores. Pois "ao conhecer melhor seu público a marca precisa ainda desenvolver um diálogo específico para os diferentes perfis de consumidores" (STRUTZEL, 2015, p. 8) e para solucionar este problema as empresas adotaram a produção de conteúdo relevante de acordo com a descrição do comprador.

Marketing de conteúdo é aliado ao digital para corresponder a consumidores mais ativos que surgiram com a popularização da internet e criar um relacionamento mais amigável com os seguidores da marca. "Utilizar canais de comunicação para compartilhar conteúdo relevante e de qualidade gera pontos de contato com a audiência. Esses pontos além de representarem a porta de entrada para relacionamentos sustentáveis, ainda atribuem autoridade a quem publica, tornando-se referência no assunto" (STRUTZEL, 2015, p. 55).

Pode ser definido como Marketing de Conteúdo "todo o conteúdo feito para educar, informar ou entreter um futuro cliente. A ideia consiste em informar as pessoas para fazer com que futuramente elas não só respeitem a sua marca e a tenham como referência, mas também se tornem clientes de sua empresa" (RESULTADOS DIGITAIS, 2018, p. 6). O conteúdo gerado pela marca para os consumidores é uma estratégia utilizada em marketing digital e permite a empresa estabelecer um relacionamento com o consumidor, promovendo um possível engajamento nas redes sociais. 


\section{ESTRATÉGIAS DE MARKETING DIGITAL}

$\mathrm{Na}$ era digital as estratégias necessitam adaptação em razão do desenvolvimento da internet e evolução da tecnologia, criando uma nova forma de comunicação para empresas e marcas. Estratégias de comunicação, de acordo com Lupetti (2007), são ações planejadas, feitas a partir de pesquisas e análises de público em ambientes externos e internos, executadas de acordo com o posicionamento e objetivos de comunicação. Estas atualizações puderam definir a comunicação na ambiência digital, o que submeteu o marketing a uma nova perspectiva, em que existem diferentes formas de comunicar-se com o público preferencial de uma determinada marca e as maneiras de se comunicar nas redes sociais devem estar alinhadas com a ambiência da plataforma escolhida e os formatos permitidos. Algumas estratégias envolvem o público para o qual a publicação foi direcionada a partir do conteúdo da postagem, pois depende do objetivo da comunicação da empresa.

"O consumidor é o mesmo, e seu comportamento on-line reflete os desejos e valores que ele traz de sua experiência na sociedade. As mudanças vêm da evolução do comportamento da sociedade" (TORRES, 2009, p. 61). A popularização da internet mudou a conduta da sociedade e esse acontecimento teve reflexo na maneira de consumir da população, o marketing digital é focado no consumidor, portanto as estratégias de comunicação utilizadas para o digital focam nas necessidades e desejos de compra de um cliente que deseja mais do que apenas comprar um produto. O quadro apresentado abaixo categoriza estratégias de marketing digital, proposta por Knoll e Ghisleni (2018), com base nos estudos de Turchi (2018).

Quadro 1 - Estratégias de marketing digital.

\begin{tabular}{|l|l|}
\hline \multicolumn{1}{|c|}{ ESTRATÉGIA DE ATUAÇÃO } & PLANEJAMENTO NAS MÍDIAS SOCIAIS COM BASE NOS OBJETIVOS \\
\hline ESTRATÉGIA DE REPUTAÇÃO DIGITAL & $\begin{array}{l}\text { Começa com o que a empresa deseja para sua marca no médio e longo prazos. Além } \\
\text { disso, as ações na web não podem estar desconectadas das estratégias globais da } \\
\text { empresa; muito pelo contrário, devem caminhar juntas. }\end{array}$ \\
\hline ESTRATÉGIA DE RELACIONAMENTO & $\begin{array}{l}\text { O mais importante nesses novos canais não é, necessariamente, arregimentar grande } \\
\text { quantidade de seguidores, mas sim estabelecer um relacionamento com aqueles } \\
\text { que realmente importam para a empresa. E esta, de sua parte, deve desenvolver a } \\
\text { habilidade de empatia, procurando compreender os anseios e interesses das pessoas } \\
\text { com as quais deseja se conectar. }\end{array}$ \\
\hline $\begin{array}{l}\text { ESTRATÉGIA DE } \\
\text { INTELIGÊNCIA COLETIVA }\end{array}$ & \begin{tabular}{l} 
Uso do meio digital para captação de oportunidades de inovação. \\
\hline ESTRATÉGIA DE MONITORAMENTO
\end{tabular} \\
$\begin{array}{l}\text { Usar ferramentas de mensuração eficazes é outro ponto importante, visto que é a } \\
\text { única forma de se aperfeiçoar e redirecionar campanhas, ainda durante sua execução, } \\
\text { se necessário. }\end{array}$ \\
\hline $\begin{array}{l}\text { ESTRATÉGIA DE CRIAÇÃO DE PERSONA } \\
\text { DA MARCA PARA REDES SOCIAIS }\end{array}$ & $\begin{array}{l}\text { leva em conta sua história, características emotivas e físicas, personalidade, va- } \\
\text { lores e ideias compatíveis com as do seu público-alvo, que poderão ser mudadas } \\
\text { com o tempo ao vivenciar experiências e aprender coisas novas. Ela pode falar } \\
\text { em nome da marca. }\end{array}$ \\
\hline
\end{tabular}




\begin{tabular}{|c|c|}
\hline ESTRATÉGIA DE CROWDSOURCING & $\begin{array}{l}\text { Uma organização faz um convite aberto para execução de uma tarefa específica, e } \\
\text { geralmente paga por isso. Os projetos costumam ser organizados no formato de } \\
\text { concurso. Muitas vezes a empresa consulta a "nuvem", onde anuncia seu problema } \\
\text { e estabelece um preço. Nesse caso, os participantes propõem soluções e a empresa } \\
\text { seleciona a melhor. As propostas podem vir de profissionais ou não. }\end{array}$ \\
\hline $\begin{array}{l}\text { ESTRATÉGIA DE DIVULGAÇÃO OU } \\
\text { PROMOÇÃO }\end{array}$ & $\begin{array}{l}\text { Mídias sociais são canais propícios para criar e estreitar relacionamentos, e isso deve } \\
\text { ser feito por meio da publicação de informações do interesse daquele público deter- } \\
\text { minado. Trabalhar o } 4 \text { Cs das mídias sociais (conteúdo, colaboração, comunidade e } \\
\text { inteligência coletiva) }\end{array}$ \\
\hline $\begin{array}{l}\text { ESTRATÉGIA DE MARKETING DE } \\
\text { CONTEÚDO }\end{array}$ & $\begin{array}{l}\text { Criação de conteúdos relevantes para pessoas que buscam informações interessantes - } \\
\text { devidamente contextualizadas e integradas com a imagem e os valores que a empresa } \\
\text { deseja mostrar para o mundo externo -, capazes de ganhar reverberação espontânea } \\
\text { nas mídias sociais. }\end{array}$ \\
\hline $\begin{array}{l}\text { ESTRATÉGIA DE MARKETING E } \\
\text { CONTEÚDO (STORYTELLING) }\end{array}$ & $\begin{array}{l}\text { O segredo está em atribuir significados emocionais a elementos técnicos por meio de } \\
\text { um contexto relevante, ter um objetivo final e, ainda, trabalhar a curiosidade ao criar } \\
\text { expectativa para que os consumidores queiram saber a continuidade da história e, } \\
\text { assim, aumentar as possibilidades de engajamento e desdobramento. }\end{array}$ \\
\hline $\begin{array}{l}\text { ESTRATÉGIA PARA AMPLIAÇÃO DE } \\
\text { NEGÓCIOS/CONSTRUÇÃO DE CONFIANÇA }\end{array}$ & $\begin{array}{l}\text { As redes sociais possuem um grande poder de mobilização, fluxo de informações } \\
\text { elevado, e tanto podem beneficiar uma marca como destruí-la. }\end{array}$ \\
\hline ESTRATÉGIA DE INTELIGÊNCIA SOCIAL & $\begin{array}{l}\text { Escutando a mídia social de maneira mais sofisticada, rastreando as atividades e inte- } \\
\text { rações dos usuários com amigos e seguidores, e depois respondendo adequadamente, } \\
\text { os dispositivos inteligentes deverão ficar ainda mais personalizados. }\end{array}$ \\
\hline
\end{tabular}

Fonte: Adaptado de Knoll e Ghisleni (2018) e Turchi (2018).

Como apresentadas na tabela, as estratégias para as plataformas digitais giram em torno do usuário que também é gerador do seu próprio conteúdo, as empresas precisaram ajustar sua comunicação a este tipo de consumidor utilizando mecanismos específicos para atender as demandas deste cliente. As mídias sociais destacam-se, com a ressalva de que não são sinônimos de redes sociais, pois segundo a autora, se referem "ao meio, ou seja, às ferramentas usadas para a comunicação, que incluem as redes sociais e os sites de Internet que permitem a criação e o compartilhamento de informações e conteúdo de pessoas para pessoas” (TURCHI, 2018, p. 141 apud KNOLL, GHISLENI, 2018, p. 11). Dos recursos utilizados pelas marcas a produção de conteúdo para seus seguidores e a mensuração de resultados através de fórmulas e taxas são os mais utilizados.

Cabe destacar uma vantagem que o marketing digital tem sobre o tradicional a facilidade de mensuração de resultados mais clara para campanhas e ações criadas pela empresa,

Por exemplo: enquanto quem faz um anúncio na televisão aberta a respeito de um produto tem muito mais dificuldade de enxergar com clareza o quão rentável foi o investimento no anúncio, o Marketing Digital permite que você consiga saber exatamente o que está dando retorno e se aquele retorno está conseguindo pagar o investimento inicial (RESULTADOS DIGITAIS, 2018, p. 24).

Segundo a empresa citada, indicadores como taxa de engajamento, que mede a porcentagem de interação entre os seguidores nas postagens da rede social da marca, e ROI (retorno sob investimento) que ajuda a perceber se o dinheiro destinado a publicidade teve o rendimento esperado, 
estas métricas mostram o andamento da ação publicitária em questão podendo indicar melhorias e adequações conforme os índices apresentados. O advento das redes sociais na internet beneficiou a elaboração de estratégias de marketing digital, disponibilizando um espaço para interconexões entre os usuários destas plataformas digitais.

\section{REDES SOCIAIS}

A relação entre pessoas pressupõe a formação de grupos que se reúnem a partir de objetivos comuns com formas distintas de se comunicar. Segundo Wasserman e Faust (tradução livre do autor, 1994, p. 1), “uma rede social é estruturada por indivíduos ou organizações, chamadas “nós”, que são conectadas por um ou mais tipos de interdependência, como amizade, interesse comum ou conhecimento". A internet facilitou a conexão entre os indivíduos, por não ser mais impedida por limites geográficos a comunicação online se tornou significativa para relações humanas.

O advento da conexão online facilitou a comunicação entre pessoas e as plataformas digitais contribuíram com isso modificando como indivíduos se relacionavam entre si e também favoreceu a interação entre marca e consumidor. "O estudo das redes sociais, assim, foca o problema de como as estruturas sociais surgem, de que tipo são, como são compostas através da comunicação mediada pelo computador e como essas interações são capazes de gerar fluxos de informações e trocas sociais que impactam essas estruturas" (RECUERO, 2009, p. 24). Com a possibilidade de se conectar através da rede mundial de computadores a forma como as marcas se comunicavam com seu público necessitou atualizações.

"No ambiente online, as redes sociais são sites em que os indivíduos possuem suas páginas pessoais, chamados de perfis, podem publicar todo o tipo de conteúdo e reunir amigos, parentes e conhecidos que formam a sua rede pessoal de relacionamento" (STRUTZEL, 2015; p. 178). Com a popularização das mídias sociais na internet o consumidor se tornou também produtor do seu próprio conteúdo, fazendo com que as marcas se esforcem mais para chamar a atenção de seus seguidores.

As mídias sociais são sites na internet que permitem a criação e o compartilhamento de informações e conteúdos pelas pessoas e para as pessoas, nas quais o consumidor é ao mesmo tempo produtor e consumidor da informação. Elas recebem esse nome porque são sociais, ou seja, são livres e abertas a colaboração e interação de todos, e porque são mídias, ou seja, meios de transmissão de informações e conteúdo (TORRES, 2009, p. 113).

Um elemento que é característico das redes sociais na internet é a sua capacidade de difundir informações através das conexões existentes entre os atores. Segundo Recuero (2009), essa capacidade alterou os fluxos de informação dentro da própria rede, o surgimento da internet proporcionou que as pessoas pudessem difundir as informações de forma mais rápida e interativa. 
Essa mudança criou novos canais e uma diversidade de novas informações circulando nos grupos sociais, com o acesso aos conhecimentos que a internet possibilitou às pessoas uma difusão de saber e entretenimento por meio da comunicação interpessoal não mais impedida pela distância geográfica (RECUERO, 2009, p. 116).

As empresas identificaram potencial mercadológico em plataformas como Instagram e Facebook, que oferecem um meio interessante para diferentes marcas. A partir disso é preciso reconhecer a possibilidade de utilização para fins publicitários, com o desenvolvimento de estratégias de marketing, a viabilidade da produção de conteúdo relevante para o consumidor, a potencialidade em gerar engajamento e analisar resultados destas estratégias, além da grande quantidade de pessoas usando essas plataformas digitais. "Com o tempo, as mídias sociais se transformaram em um espaço muito interessante para quem procura novos canais para aplicar Marketing Digital" (RESULTADOS DIGITAIS, 2018, p. 13). Segundo informações disponíveis em Facebook (2019, online) o número de usuários ativos diariamente da plataforma ultrapassou 1.56 milhões de pessoas em 2019, esse dado pode ser considerado um exemplo dos motivos que levaram as marcas a se colocarem como participantes ativos em mídias sociais digitais e utilizá-las como ferramentas de marketing.

\section{INSTAGRAM}

É uma rede social, focada em mobile, criada em 2010 por Kevin Systrom e Mike Krieger, que possui um bilhão de usuários ativos por mês, estimativa feita em junho de 2018 (INSTAGRAM, 2018). A plataforma permite que os usuários postem fotos e vídeos em seus feeds, ou criem stories que permanecem 24 horas em seus perfis e a interação entre usuários é feita por meio de curtidas, comentários e mensagens diretas. Outra característica é a disponibilidade de uma ambiência empresarial, que compreendem formas de patrocinar postagens e mensurar os resultados de cada publicação, para todos os formatos.

“Hoje o Instagram é, sem dúvida, uma das redes sociais com mais potencial de investimento atual. A rede cresceu impressionantes $23 \%$ ao ano, mais do que o dobro de crescimento das outras redes sociais" (ROCKCONTENT, 2017). Segundo a pesquisa Contende Trends 2018 a rede social é a segunda mais utilizada por empresas brasileiras, com participação de $80,8 \%$ das empresas, sendo que a primeira rede social mais utilizada é o Facebook com 97,7\%, entretanto, cabe ressaltar que os resultados mostram que ainda na questão de preferência o Instagram ocupa o primeiro lugar entre as marcas, com 3,6 pontos em uma escala de cinco em que um ponto representa que a rede social é pouco eficaz e cinco muito eficaz.

O Instagram possui atualmente quatro formatos principais para publicações que são: foto, vídeo, stories e IGTV, que são utilizados por marcas de diversas formas, "a ideia é apresentar o produto ou serviço sempre como o melhor" (REZER, et al., 2018, p. 5). Dessa maneira as empresas 
usufruem do potencial que a plataforma oferece para colocar-se em evidência para seu público-alvo. Como premissa para a redução de material a ser estudado, foram utilizadas apenas publicações do formato foto, que de acordo com o Instagram (2018, online) "as postagens feitas em formato de fotos foram os primeiros disponibilizados pelo aplicativo, a rede social permite postagem em formato vertical (1440 x 1080 pixels), horizontal (1080 x 566 pixels) ou quadrado (1080 x 1080 pixels), possibilitando a ferramenta carrossel que permite até dez fotos serem postadas de uma vez".

Os formatos apresentados favorecem a produção de conteúdo por parte das marcas, e com isso engajar e criar relacionamento com seguidores, fortalecendo assim sua imagem. "Fica evidente que um conteúdo cuidadosamente produzido consegue alcançar os resultados almejados, ou seja, a forma como o discurso publicitário será efetuado definirá a verdade em seu discurso, assim induzindo o desejo do público a consumir seus produtos/serviços" (REZER, et al., 2018, p. 5). Uma rede social com maior disponibilidade de formatos de postagens pode enriquecer as possibilidades de como o conteúdo é apresentado aos seguidores, podendo gerar assim engajamento positivo para a empresa.

\section{ENGAJAMENTO}

O trabalho de mensurar dados em redes sociais tem como base a interação dos seguidores e como eles se comportam perante as publicações postadas na rede social em questão. Para isso a métrica utilizada no sentido de viabilizar tal mediação é o cálculo da taxa de engajamento apresentado através de uma pirâmide onde o objetivo é fazer com que os consumidores alcancem o topo e se tornem curadores da marca, conforme pode ser observado na figura a seguir.

Figura 1 - Pirâmide do engajamento

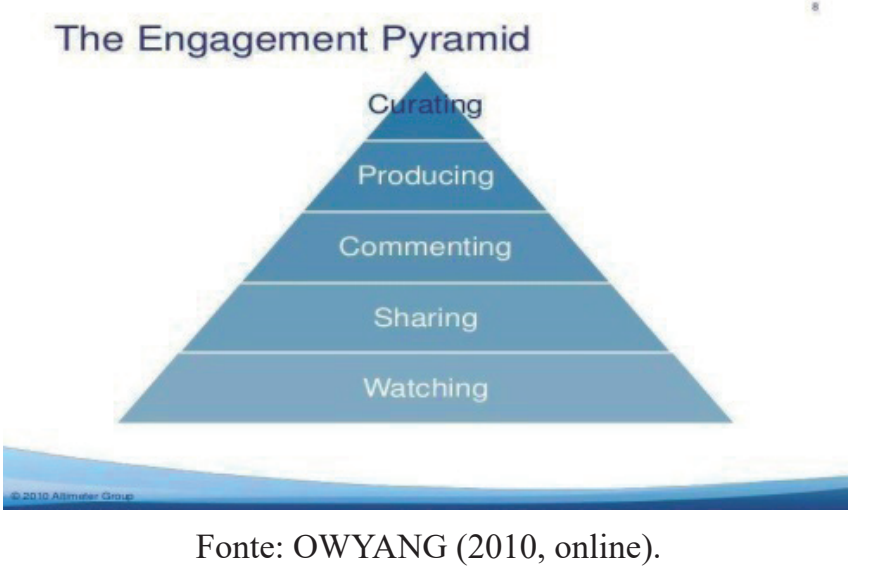

A pirâmide do engajamento, descrita por Jeremiah Owyang em Understand Your Customers' Social Behaviors, é constituída, da base para o topo, pelos que apenas assistem o conteúdo, ou seja, não comentam, curtem ou compartilham apenas procuram por opiniões para tomar uma decisão ou a utilizam como entretenimento. $\mathrm{Na}$ base da pirâmide, está situado o usuário que apenas observa e não 
tem nenhuma reação para com as postagens, já em um nível acima são os 'compartilhadores', estes têm o propósito de apenas compartilhar o conhecimento e informação produzidos pelas marcas.

O próximo segmento da pirâmide, são os 'comentadores' que participam, contribuem com o conteúdo da postagem e respondem outros usuários. A parte acima representa os produtores, este tipo de usuário cria e compartilham seu próprio conteúdo e quer ser reconhecido pela marca além de permitir expressar sua identidade própria. No topo da pirâmide, está o usuário curador de conteúdo, que não só produz seu próprio material sobre a marca, mas também faz moderação de comunidades online.

Para o entendimento da estrutura apresentada se faz necessário entender que engajamento "é o nível máximo de relacionamento entre a marca e o consumidor, onde este acompanha ativamente o conteúdo publicado" (STRUTZEL, 2015, p. 91). A técnica consiste em manter e mensurar o relacionamento com os seguidores da marca, a relação entre empresa e consumidor, comumente, indica uma taxa de engajamento adequada. Disponibilizar conteúdo relevante e não ter uma relação com o seguidor, respondendo comentários e com o público, pode acarretar um alto nível de relacionamento. Entretanto, a fórmula apresentada considera uma visão geral das reações e comentários, mas não se propõe a distinguir entre as opiniões positivas ou negativas, ou fazer qualquer juízo de valor. Atender as necessidades dos seguidores da marca pode tornar mais fácil a distinção de um índice positivo ou negativo.

Figura 2 - Fórmula do engajamento.

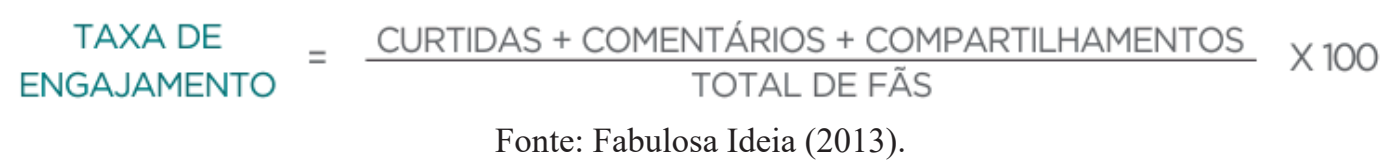

A figura acima apresenta a fórmula para calcular a taxa de engajamento, difundida pela Fabulosa Ideia que considera para fins de cálculo o número de curtidas, comentários, compartilhamentos e ainda leva em conta o total de fãs (ou seguidores) de uma página. Já que no Instagram não existe a ferramenta para compartilhamento, quando aplicada nesta rede social a fórmula não considera esta variável. O engajamento diz respeito ao nível de interação dos diferentes tipos de usuários com o conteúdo publicado, segundo Strutzel $(2015$, p. 16) "o conteúdo é a mola propulsora que movimenta a internet, e o engajamento se tornou a principal referência de como conteúdo impacta as pessoas".

O relacionamento estabelecido atualmente com os seguidores de uma marca, se comparado com a forma como era estabelecido antigamente, permite a identificação de alterações ao longo do tempo. O que acarretou em uma mudança de postura por parte dos profissionais responsáveis pela publicidade, mudando o foco da comunicação para os interesses do consumidor, levando em conta a disponibilidade e acesso às informações favorecidas pela popularização da internet. Outro ponto importante é a utilização de métricas que modificou a forma de avaliar o comportamento do consumidor e de como e se a campanha publicitária veiculada está recebendo atenção. 


\section{PROCEDIMENTOS METODOLÓGICOS}

A presente pesquisa apresenta natureza qualitativa, a definição por esta natureza leva em conta a análise da essência do conteúdo proposto pelo perfil oficial da série Grey’s Anatomy no Instagram e o cálculo da taxa de engajamento, tendo sido considerado 10 postagens previamente selecionadas. Assim como as estratégias utilizadas em cada publicação feita pelo seriado para engajar seus seguidores o índice de engajamento tem como premissa identificar a eficácia do conteúdo. De acordo com, Michel (2009, p. 38)

A pesquisa qualitativa considera que há uma relação dinâmica, particular, contextual e atemporal entre o pesquisador e o objeto de estudo. Por isso, carece de uma interpretação de fenômenos à luz do contexto, do tempo, dos fatos. $\mathrm{O}$ ambiente da vida real é a fonte direta para obtenção dos dados, e a capacidade do pesquisador de interpretar essa realidade, com isenção e lógica, baseando-se em teoria existente, é fundamental para dar significado às respostas.

A técnica estabelecida para esta pesquisa foi análise de conteúdo que conforme Bardin (1977, p. 38) é "[...] um conjunto de técnicas de análise das comunicações, que utiliza procedimentos sistemáticos e objetivos de descrição do conteúdo das mensagens". O autor ainda acrescenta que este procedimento tem por finalidade a descrição objetiva, sistemática e quantitativa do assunto manifesto pela comunicação. Foi considerado que cada postagem tem um número de comentários e curtidas distintos, permitindo assim calcular a taxa de engajamento de cada uma delas para a identificação da aceitação dos tipos de conteúdo pelos fãs do seriado.

O material analisado na presente pesquisa foi obtido através do perfil oficial da série de televisão Grey’s Anatomy na plataforma digital instagram,@greysabc, do dia 27 de setembro de 2018 a 16 de maio de 2019, período de exibição da $15^{a}$ temporada do seriado na rede de televisão norte americana American Broadcasting Company (ABC). Para a análise foram selecionadas 10 publicações, dentre as 420 observadas, no período de 26 de setembro de 2018 à 17 de maio de 2019, a seleção das postagens foi realizada de forma que não as desvinculasse dos acontecimentos do seriado, para reduzir o material de análise apenas o formato foto foram explorados. As publicações foram elencadas a partir da identificação do maior número de curtidas apoiado na divisão dos 25 episódios da $15^{\text {a }}$ temporada do seriado em cinco partes de cinco capítulos cada. Por exemplo: na parte um encontram-se os episódios um a cinco, neste período foram feitas 21 postagens em formato foto, dessas foram identificadas as duas mais curtidas para serem analisadas.

Considerando a identificação das publicações foi constatado que algumas das partes possuíam postagens com conteúdo semelhante, sendo assim para o presente estudo foram desconsideradas e sucedida por outro post com temática diferente, tendo em vista o número de curtidas. Para organizar as informações apuradas as publicações foram colocadas em um quadro de análise, a partir da divisão prévia do seriado para a eleição das publicações a serem exploradas, utilizando critérios previamente 
apresentados no capítulo referente à apresentação dos procedimentos metodológicos com as respectivas especificações.

Para realizar o cálculo da taxa de engajamento foi necessário levar em consideração o número de seguidores do perfil do programa de televisão na plataforma digital referida, que no momento da coleta (05/05/2019), atingia 5,8 milhões de pessoas. A partir dos estudos de Turchi (2018) e Ghisleni e Knoll (2018) foi possível categorizar as estratégias de marketing e de produção de conteúdo digital feitos pela série em seu perfil na rede social.

A $15^{\text {a }}$ temporada estreou no canal estadunidense ABC no dia 27 de setembro de 2018 e no Brasil o primeiro episódio foi ao ar dia 27 de outubro de 2018, pelo canal de televisão por assinatura Canal Sony. A temporada contou com 25 episódios (GREY'S ANATOMY BR, 2019, online) e foi possível observar de maneira empírica para a confecção da presente pesquisa que o conteúdo criado para o Instagram oficial da série tem o propósito de gerar sensibilização do público que segue o perfil na rede social.

O perfil oficial da série Grey’s Anatomy (@greysabc) na plataforma digital Instagram, conta com mais de cinco milhões e meio de seguidores e mais de 1.400 publicações no feed (INSTAGRAM, 2019). É mantido com postagens diárias, sobre os acontecimentos da série ou no backstage com os atores, repercussões dos acontecimentos, avisos de novos episódios e postagens institucionais com frases marcantes e momentos importantes dos personagens de todo o decorrer da série. Durante o período de exibição da $15^{\mathrm{a}}$ temporada da série, as postagens iniciaram em 30 de agosto de 2018 e finalizaram em 17 de maio de 2019, totalizando 471 postagens durante oito meses e 17 dias, com conteúdos variados direcionados aos fãs do seriado. Cada uma das postagens possui um número de comentários e de curtidas que se diferem dependendo do post, o que possibilita a verificação da taxa de engajamento de cada uma. Entre as postagens o conteúdo também se distingue, mantendo a essência do seriado e o assunto de cada postagem tem influência na mensuração do engajamento, esta relação foi o foco de análise do presente artigo.

\section{GREY'S ANATOMY}

A série estreou no dia 27 de março de 2005 na rede de televisão americana ABC e no Brasil é transmitida pelo Canal Sony com o nome de "A Anatomia de Grey". O seriado também está disponível no serviço de streaming Netflix. Criada e produzida por Shonda Rhimes, o seriado atualmente conta com 15 temporadas e 338 episódios. O elenco principal do seriado é composto por 11 atores dentre eles, Ellen Pompeo (Meredith Grey), Justin Chambers (Alex Karev), Chandra Wilson (Miranda Bailey), Caterina Scorsone (Amélia Shepherd) e Jesse Williams (Jackson Avery), conforme indicado no site ABC (online)

“A Doutora Meredith Grey e um time de médicos no Hospital Grey Sloan Memorial que enfrentam decisões de vida ou morte em uma rotina diária, juntos descobrem que na medicina nem 
relações emocionais podem ser definidas preto no branco" (Tradução livre do autor, ABC, 2019). Os assuntos tratados abordam temas como racismo, homofobia, machismo e relacionamentos abusivos. Na $15^{\text {a }}$ temporada o seriado atingiu o número de 331 episódios se tornando o maior drama médico da televisão, batendo o recorde da série Plantão Médico veiculado entre final dos anos 90 e início dos anos 2000. A marca foi comemorada com um episódio especial dirigido por Chandra Wilson (ADOROCINEMA, 2019, online).

A criação de Shonda Rhimes originou três spinoffs com personagens já conhecidos pelo público. A produtora também criou Private Practice (2007 - 2013) apresentando a vida pós Grey’s Anatomy, em uma clínica de fertilização em Los Angeles, da personagem de Kate Walsh, que interpretou a Dr. Addison Montgomery durante 59 episódios na série. A atriz fez parte do elenco principal ou como convidada, protagonizou seis temporadas do seriado apresentando novos personagens para o público como a Dr. Amelia Shepherd que posteriormente faria parte do elenco principal de Grey's Anatomy. O seriado Station 19 (2018) acompanha o dia a dia do corpo de bombeiro e socorristas de Seattle, a ligação com Grey’s Anatomy é o personagem Ben Warren, interpretado por Jason George, que é casado com a médica chefe do hospital, Dr. Miranda Bailey (Chandra Wilson). Antes de ser paramédico o personagem incorporava o time de residentes do Grey-Sloan Memorial Hospital (Tradução livre do autor, ABC, online). Grey's B-Team (2018) é uma minissérie online de apenas uma temporada que acompanha o primeiro dia dos novos internos no hospital (tradução livre do autor, ABC, online), a produção tem seis episódios disponibilizados gratuitamente pela rede de televisão ABC.

A partir das produções citadas foi possível a realização de episódios crossovers entre as séries, principalmente nas últimas duas temporadas de Grey’s Anatomy que em determinados capítulos o seriado 'cruza' com Station 19 e vice-versa. Essa integração gerou participações dos personagens e episódios especiais com duas horas de duração em que a história é a mesma para as duas produções, tendo sido divulgado no Instagram oficial com postagens específicas sobre. O seriado propõe uma visão da sociedade atual pelos olhos dos profissionais do hospital e suas experiências de vida. Ao expandir o universo da série por meio desses cruzamentos entre as séries, faz com que as tramas dos personagens e os acontecimentos que circundam os seriados se dividam entre os programas de televisão, podendo uma história começar em um e terminar em outro, propondo para os espectadores acompanharem ambas as séries.

\section{APRESENTAÇÃO E ANÁLISE DOS DADOS}

Através das postagens analisadas e os dados coletados foi possível identificar diferentes estratégias de produção de conteúdo digital e tipos de conteúdo utilizados pela série de televisão Grey's Anatomy no Instagram, assim como a resposta dos seguidores nas postagens, por meio da taxa de engajamento, utilizando o número de curtidas e comentários. Para Strutzel (2015, p 56) 
"marketing de conteúdo nada mais é que uma estratégia estruturada para elaborar e disseminar conteúdo relevante com objetivo de atrair e reter clientes, fortalecendo a presença digital da marca". Ao levar em consideração as propostas do autor é possível afirmar que o conteúdo influencia diretamente na taxa de engajamento.

Os acontecimentos no decorrer do seriado também devem ser levados em consideração para a análise da taxa de engajamento, pois a reação dos fãs aos episódios tem relação direta com os resultados dos cálculos. Assim é possível inferir que as postagens analisadas que possuem conteúdo dire-

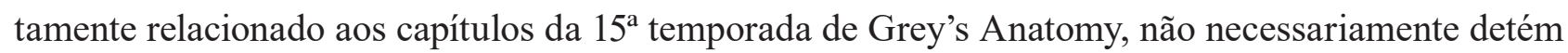
um índice de engajamento maior do que posts não ligados aos acontecimentos do seriado.

Durante a análise foi possível notar a linguagem descontraída utilizada pela série, o uso de hashtags e emojis além das referências a frases e acontecimentos do seriado, nas legendas e ou na imagem que constrói a postagem. O que demonstra a preocupação dos gerenciadores da página ao criar o conteúdo para os fãs, pois como afirma Kotler (2010, p. 203) "ao conquistar um cliente, deve-se manter com ele um bom relacionamento". Dentre as postagens avaliadas pode-se notar a presença de estratégias de relacionamento, que promovem a interação entre os seguidores, como afirma Turchi (2018) o mais importante não é necessariamente arrecadar quantidade de seguidores, mas sim estabelecer um relacionamento com aqueles que importam.

Quadro 3 - Análise de dados

\begin{tabular}{|c|c|c|}
\hline & Postagem & Análise dos dados \\
\hline \multirow{6}{*}{ 1) } & & Número de curtidas: 235.200 \\
\hline & & Número de comentários: 1355 \\
\hline & & Taxa de engajamento: $4,8 \%$ \\
\hline & & Estratégia de marketing digital: Estratégia de marketing e conteúdo (storytelling). \\
\hline & & Tipo de conteúdo: spoiler / volta de personagem. \\
\hline & & Legenda: "Welcome back Teddy \#GreysAnatomy". \\
\hline \multirow{6}{*}{ 2) } & & Número de curtidas: 325.469 \\
\hline & & Número de comentários: 2.742 \\
\hline & & Taxa de engajamento: $5,65 \%$ \\
\hline & & Estratégia de marketing digital: Estratégia de marketing de conteúdo. \\
\hline & & Tipo de conteúdo: spoiler com ênfase em personagem do elenco original. \\
\hline & & Legenda: “ف \\
\hline
\end{tabular}




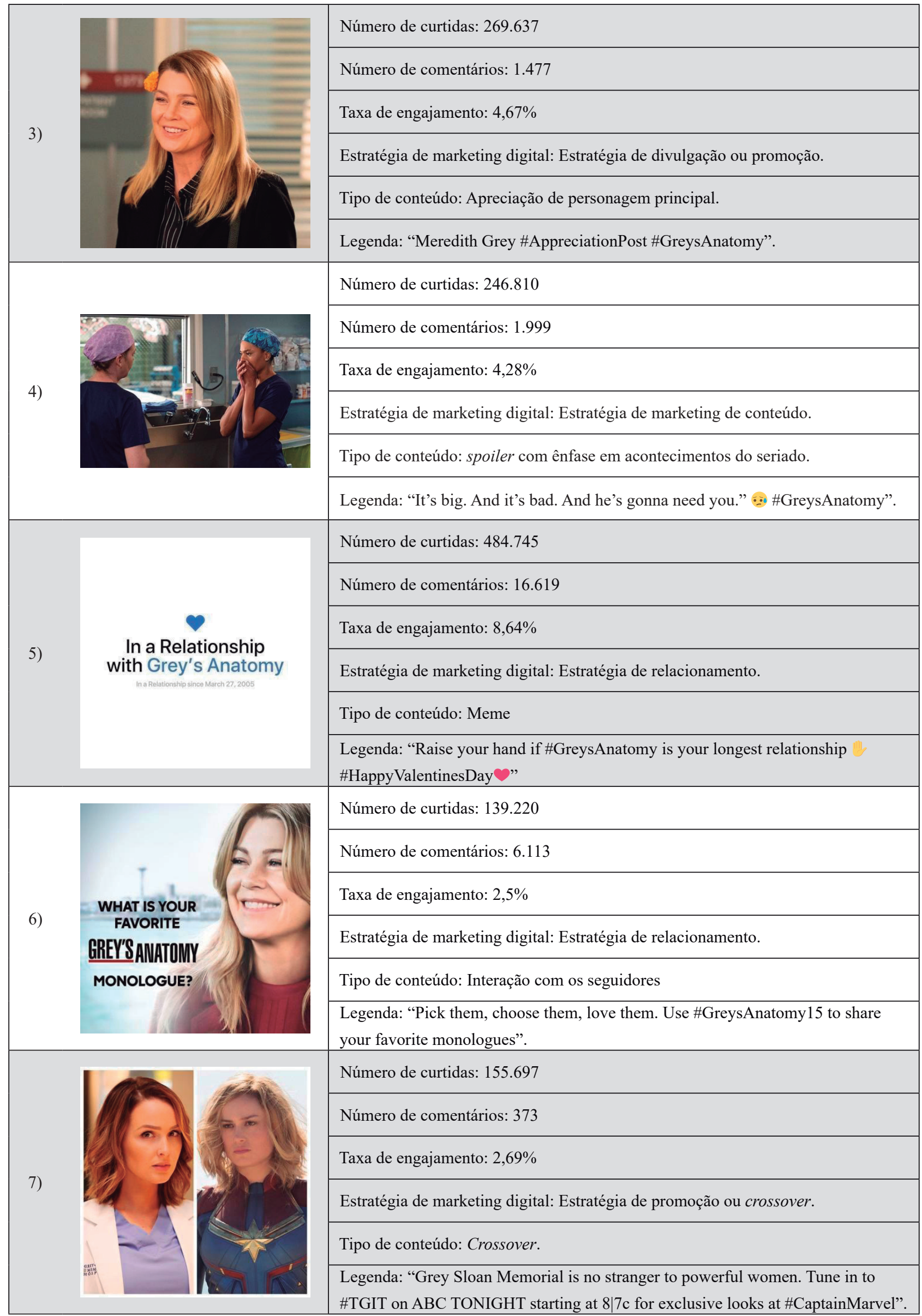




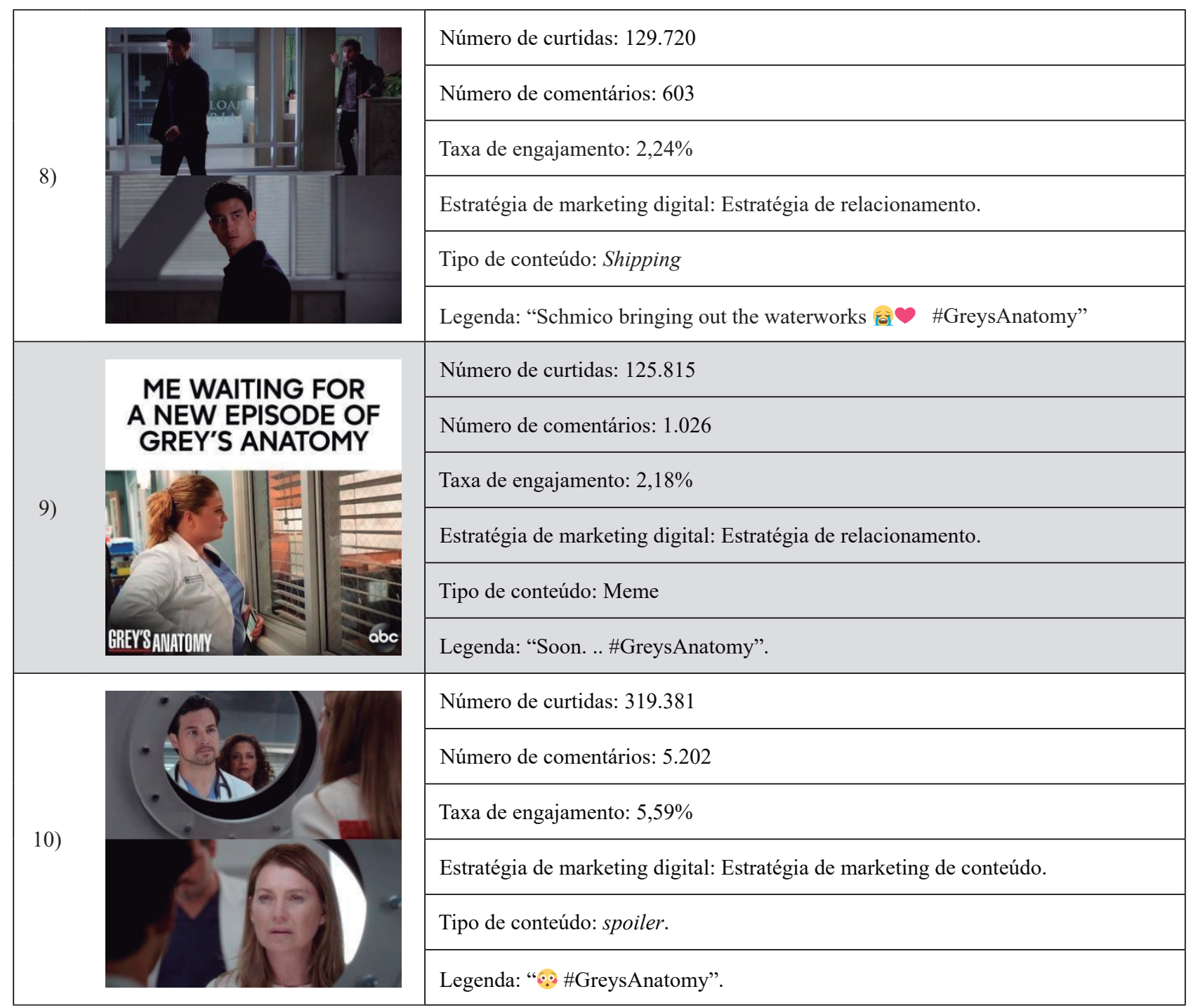

Fonte: elaboração dos autores.

O quadro apresenta as publicações feitas durante o período de exibição do $1^{\circ}$ ao $25^{\circ}$ episódio da temporada, escolhidas a partir do número de curtidas. Durante a coleta dos dados pode-se notar a utilização de estratégias de marketing digital e diferentes tipos de conteúdo, dentre os 10 posts selecionados. Uma delas é a estratégia de marketing e conteúdo (storytelling) que de acordo com Knoll e Ghisleni (2018) significa "atribuir significados emocionais a elementos técnicos por meio de contexto relevante". Presente na postagem 1 que trata de uma personagem que não fazia mais parte do elenco principal que retornou nesta $15^{\mathrm{a}}$ temporada, exposição do regresso da figura, faz com que a postagem se caracterize desta forma.

Outra estratégia recorrente é a de estratégia de marketing de conteúdo que se configura como “criação de conteúdos relevantes para pessoas que buscam informações interessantes" (KNOLL; GHISLENI, 2018). Nas postagens dois, quatro e dez, que retratam acontecimentos significativos do seriado, através das reações que os personagens têm na imagem postada. Esta estratégia é geralmente ligada ao tipo de conteúdo spoiler que pode ser definido como uma "descrição de um desenvolvimento importante da trama em um programa de televisão, filme ou livro que, se conhecido anteriormente, 
pode reduzir a surpresa ou suspense para um espectador ou leitor iniciante" (OXFORD, 2019, online). A ABC propõe estas postagens com o intuito de instigar a curiosidade do seguidor do perfil no Instagram sobre o episódio que será exibido na noite em que a publicação foi divulgada.

Ao usufruir da imagem da personagem principal do seriado Meredith Grey, na 15 temporada, a empresa que gerencia o perfil na rede social de Grey’s Anatomy presume a estratégia de promoção ou divulgação que tem por proposta "publicação de informações do interesse do público" (KNOLL; GHISLENI, 2018). Podemos inferir que o emprego da imagem da protagonista da série, na postagem três, é um tipo de conteúdo que tem a intenção de engajar o público.

Para tentar se relacionar com seus seguidores a estratégia escolhida para a postagem de número 6 foi a de relacionamento que tem por conceito "[...] estabelecer um relacionamento com aqueles que realmente importam para a empresa" (TURCHI, 2018). Ao aplicar conteúdos que indagam o público, como utilizado na postagem seis, que pergunta aos fãs qual o monólogo favorito da série. Ou até mesmo utilizar de memes como no post nove, que tem por objetivo de dar um tom mais humorado os espectadores do perfil.

É possível observar na postagem cinco que uma data comemorada nos Estados Unidos o dia de São Valentim, conhecido como dia dos namorados se tornou conteúdo de interação para a ABC, que administra a página na rede social Instagram do seriado. As situações vividas pelos personagens no decorrer da série, como por exemplo, no post oito em que é apresentado um dos casais, formados pelo programa, em um momento de clímax, se tornou uma chance de se relacionar com os fãs e seguidores do Instagram oficial.

Durante a análise dos dados, também foi possível identificar uma publicação em que é possível observar a estratégia de promoção, com a ressalva de não estar divulgando apenas o seriado, mas também o trailer de um filme que iria ser exibido durante os comerciais publicitários no período do episódio daquela semana específica. Pode-se perceber que ao criar este crossover entre duas mídias diferentes, televisão e cinema, tanto o seriado como o filme se beneficiaram com o conteúdo desta publicação.

Ao considerar todos os cálculos referentes a taxa de engajamento das postagens analisadas, é possível indicar que, apesar de existir uma preferência da $\mathrm{ABC}$ pela estratégia de relacionamento, não necessariamente são as que mais engajaram os seguidores, devido ao público estar apegado à imagem dos personagens recorrentes do seriado. Também está relacionado aos acontecimentos apresentados ao decorrer do seriado, por exemplo, postagens sobre um episódio que não foi bem aceito pelos espectadores provoca-os a pararem de acompanhar a temporada do programa, o que acarreta no declínio do índice de engajamento. A partir das observações elencadas anteriormente, infere-se que a preferência do público está diretamente relacionada as casualidades da série e o apego a figuras criadas pelo programa, como os personagens e os lugares em que a trama se passa, o que cria essa afeição por parte dos fãs. 


\section{CONSIDERAÇÕES FINAIS}

O desenvolvimento da comunicação está relacionado à evolução da tecnologia e das redes sociais e o avanço deste conhecimento técnico fez com que empresas e marcas buscassem seus espaços perante as mudanças proporcionadas pelo progresso tecnológico. Ao levar em consideração a facilidade que as mídias sociais proporcionaram com o passar dos anos, as estratégias publicitárias para atrair e engajar clientes precisaram acompanhar este processo. É possível indicar uma ferramenta que se popularizou nos últimos cinco anos decorrentes desta "evolução", os serviços de streaming como a Netflix, que democratizou o acesso ao mercado das séries e filmes por um preço acessível.

Todas estas mudanças também levaram o consumidor a se adaptar a novas plataformas e conteúdos diversificados, criando novas expectativas para a comunicação publicitária, pois com novos públicos, com características distintas decorrentes das diferentes gerações, é necessário encontrar novas estratégias para conquistá-los. Ao considerar que uma das maiores redes sociais atualmente é o Instagram, por ter mais de 1 bilhão de usuários ativos no mundo (INSTAGRAM, 2018), a sua importância para o mercado publicitário é significativa, já que existe um número considerável de pessoas que utilizam a rede social, faz com que muitas empresas estejam presentes nesta plataforma. Os seriados, para amplificar sua divulgação, fazem uso desta rede social como meio de comunicação com seus espectadores através da produção de conteúdos direcionado a este público, objetivando com isso aumentar a visibilidade e o engajamento com relação à série.

O seriado Grey's Anatomy, objeto de estudo desta pesquisa, exibiu a sua $15^{\circ}$ temporada no ano de 2018 e possui um grande número de seguidores no Instagram, alcançando a marca de 5,8 milhões, com postagens diárias e conteúdos diversos, como informações sobre os personagens, bastidores e chamadas para os novos episódios. A preocupação da ABC, que coordena a administração do perfil, com relação a postagens que possam engajar o público do seriado é perceptível, no momento em que utiliza de técnicas de marketing digital e de conteúdo para conseguir a atenção e promover um relacionamento com os seguidores, desta forma fazendo com que a taxa de engajamento se eleve.

Diante do que foi exposto, é possível identificar que a presente pesquisa contribui com a área de comunicação, pois permitiu a compreensão de como a série Grey’s Anatomy se comunica via Instagram com seus fãs. E ainda, apontou a caracterização das estratégias e conteúdos utilizados para engajar o público do seriado, indicando os parâmetros utilizados para que as estratégias sejam mais efetivas e com isso os índices da taxa de engajamento possam ser ampliados. Neste sentido, indica-se como percurso para novos estudos, com foco semelhante e mesma temática da pesquisa realizada, buscar compreender como a comunicação de outros seriados de televisão estão presentes nas redes sociais. 


\section{REFERÊNCIAS}

ADORO CINEMA. GREY'S ANATOMY SUPERA PLANTÃO MÉDICO COMO MAIOR DRAMA MÉDICO DA TELEVISÃO. Disponível em: https://bit.ly/3lVwNYh. Acesso em: jun. 2019.

BARDIN, Laurence. Análise de conteúdo. Lisboa: Edições 70, 1977.

BELLAMY, Roberto V. ; MCDONALD, Daniel G. e WALKER, James R.The spin-off as television program form and strategy Journal of broadcasting and electronic media. 2009.

CNBC. INSTAGRAM CORSSES 1 BILLION MONTHY ACTIVE USERS. Disponível em: https://cnb.cx/3BYiRCf. Acesso em abril de 2019.

CONTENT TRENDS. ROCK CONTENT. Disponível em: https://bit.ly/3jhtzwn. Acesso em: maio de 2019.

INSTAGRAM: @greysabc. Disponível em: https://www.instagram.com/greysabc/.

INSTAGRAM: About us. Disponível em: https://www.instagram.com/about/us/.

FABULOSA IDEIA. Mensure o engajamento de seus fãs. Disponível em: https://bit.ly/3aOAlq8. Acesso em março 2019.

GABRIEL, Martha. Marketing na era digital. Conceitos, plataformas e estratégias. São Paulo: Novatex, 2010.

GREY'S ANATOMY. Disponível em: http://www.greysanatomy.com.br/. Acesso em junho de 2019.

INSTAGRAM. WELCOME TO IGTV. Disponível em: https://bit.ly/3jgzn9k. Acesso em abril de 2019.

KOTLER, Philip; KARTAJAYA; Hermawan; SETIAWAN, Iwan. Marketing 4.0: do tradicional ao digital. Rio de Janeiro: Sextante, 2017.

KNOLL, Graziela Frainer; GHISLENI, Taís Steffenello. Estratégias de Comunicação em Mídias Digitais. Santa Maria. 2018. 
LUPETTI, Marcélia. Gestão Estratégica da Comunicação Mercadológica. São Paulo: Thomson Learning, 2007.

LUPETTI, Marcélia. Planejamento de comunicação. 3. ed. São Paulo: Futura, 2002.

MICHEL, Maria Helena. Metodologia e Pesquisa Científica em Ciências Sociais. 3. ed. São Paulo: Atlas, 2015.

OWYANG, Jeremiah. Understand Your Customers'Social Behaviors. Disponível em: https://bit.ly/ 3 pgEABT. Acesso em junho de 2019.

OXFORD LEARNER'S DICTIONARIES. Disponível em: https://www.oxfordlearnersdictionaries.com. Acesso em: jun. 2019.

REZER, Rafaela Milani; KNOLL, Graziela Frainer; GHISLENI, Taís Steffenello. Posts publicitários no instagram: Análise de formatos, funções e conteúdo advertising. Disciplinarum Scientia, Série: Artes, Letras e Comunicação, v. 19, n. 1, p. 35-43, 2018.

RECUERO, Raquel. Redes sociais na internet. 2. ed. Porto Alegre: Sulina, 2011.

SAAD, Elizabeth. Estratégias 2.0 para a mídia digital: internet, informação e comunicação. 2. ed. São Paulo: SENAC, 2008.

RESULTADOS DIGITAIS. O guia definitivo do marketing digital. 2018.

REVOREDO, Tatiana Trícia de Paiva. A tecnologia "streaming" (fornecida pela Netflix, Spotify e outros) no contexto do direito tributário brasileiro e do direito digital. In: Âmbito Jurídico, Rio Grande, XX, n. 158, mar 2017. Disponível em: https://bit.ly/3jgaOtm. Acesso em maio 2019.

REDATOR, Rock Content. Marketing no Instagram: o guia da Rock Content. 2017. Disponível em: https://bit.ly/3jgz5iK. Acesso em maio de 2019.

RIBEIRO, Maria Laura Cabral Saldanha. A cultura e o branding de moda na comunicação digital: o Instagram e a geração de sentidos. Lisboa, 2018. Disponível em: http://hdl.handle.net/10451/37237. 
STRUTZEL, Tércio. Presença digital: estratégias eficazes para posicionar sua marca pessoal ou corporativa na web. Rio de Janeiro, RJ: Alta Books, 2015.

TURCHI, Sandra R. Estratégias de marketing digital e e-commerce. 2. ed. São Paulo: Atlas, 2018.

TECMUNDO. INSTAGRAM TEM 1 BILHÃO DE USUARIOS ATIVOS MÊS. Disponível em: https://bit.ly/30KmZIF. Acesso em março de 2019.

TORRES, Cláudio. A Bíblia do Marketing Digital: tudo o que você queria saber sobre marketing e publicidade na internet e não tinha a quem perguntar. São Paulo: Novatec, 2009.

TRINDADE, Nathane Spencer. A presença digital no instagram da marca adidas em 2017. Santa Maria, 2017.

TURCHI, Sandra R. Estratégias de marketing digital e e-commerce. 2.ed. São Paulo: Atlas, 2018.

TV LINE. GREY'S ANATOMY SUPER-SIZED: ABC INCREASES SEASON 15 EPISODE ORDER. Disponível em: https://bit.ly/3AY76KV. Acesso em: maio de 2019.

WASSERMAN, Stanley e FAUST, Katherine Stanley. Social Network Analysis: Methods and Applications. University of Illinois Wasserman, Urbana-Champaign) Cambridge University Press, 25 de nov de 1994 - 825 páginas. 